\title{
Microcirculatory changes during open label magnesium sulphate infusion in patients with severe sepsis and septic shock
}

\author{
Andrius Pranskunas ${ }^{1 \dagger}$, Namkje AR Vellinga ${ }^{2,3 \dagger}$, Vidas Pilvinis ${ }^{1}$, Matty Koopmans $^{2}$ and E Christiaan Boerma ${ }^{2,3^{*}}$
}

\begin{abstract}
Background: Microcirculatory alterations play a pivotal role in sepsis and persist despite correction of systemic hemodynamic parameters. Therefore it seems tempting to test specific pro-microcirculatory strategies, including vasodilators, to attenuate impaired organ perfusion. As opposed to nitric oxide donors, magnesium has both endothelium-dependent and non-endothelium-dependent vasodilatory pathways.

Methods: In a single-center open label study we evaluated the effects of magnesium sulphate (MgS) infusion on the sublingual microcirculation perfusion in fluid resuscitated patients with severe sepsis and septic shock within the first 48 hours after ICU admission. Directly prior to and after 1 hour of magnesium sulphate (MgS) infusion (2 gram) systemic hemodynamic variables, sublingual SDF images and standard laboratory tests, were obtained.

Results: Fourteen patients (12 septic shock, 2 severe sepsis) with a median APACHE II score of 20 were enrolled. No significant difference of the systemic hemodynamic variables was found between baseline and after MgS infusion. We did not observe any significant difference pre and post MgS infusion in the primary endpoint microvascular flow index (MFI) of small vessels: 2.25(1.98-2.69) vs. 2.33(1.96-2.62), $p=0.65$. Other variables of microcirculatory perfusion were also unaltered. In the overall unchanged microvascular perfusion there was a nonsignificant trend to an inverse linear relationship between the changes of MFI and its baseline value $(y=-0.7260 x$ $+1.629, r^{2}=0.270, p=0.057$ ). The correlation between baseline Mg concentrations and the change in MFI preand post MgS infusion was non-significant $\left(r_{s}=-0.165, p=0.67\right)$.
\end{abstract}

Conclusions: In the setting of severe sepsis and septic shock sublingual microcirculatory alterations were observed despite fulfillment of sepsis resuscitation guidelines. After infusion of a limited and fixed dose of MgS, microcirculatory perfusion did not improve over time.

Trial registration: ClinicalTrials.gov NTC01332734.

\section{Background}

Microcirculatory dysfunction in sepsis is crucial in the pathogenesis of organ dysfunction and consists of a cascade of mechanisms, which involves many cells, such as endothelial cells, smooth muscle cells, red blood cells and leukocytes [1]. New microcirculatory imaging techniques, such as orthogonal polarization spectral (OPS) imaging [2] and its technical successor sidestream dark field (SDF) imaging [3], have allowed direct observation

\footnotetext{
*Correspondence: e.boerma@chello.nl

+ Contributed equally

2Department of Intensive Care Medicine, Medical Center Leeuwarden, Henri Dunantweg 2, Leeuwarden, 8901 BR, the Netherlands

Full list of author information is available at the end of the article
}

of the microcirculation at the bedside. De Backer et al. [4] were the first to report that the observed microcirculatory alterations in sepsis were associated with morbidity and mortality, irrespective of correction of global hemodynamic variables [5].

Therefore, other strategies that aim to attenuate microcirculatory dysfunction directly at the level of the microcirculation, have been tested. According to Poiseuille's Law, blood flow through a vessel is directly proportional to the driving pressure along the vessel and its radius to the fourth power, and inversely proportional to the length of the vessel and the dynamic blood viscosity. Theoretically, vasodilators should be able to

\section{Biomed Central}


increase blood flow via a change in vessel diameter at the entrance of the microcirculation and recruit microcirculatory perfusion in volume resuscitated patients [6]. Stimulation of endothelium-dependent vasodilation by topical application of acetylcholine was effective in the recruitment of shut-down capillaries in septic patients, thus challenging the concept of vasoplegia [7]. It suggested that endothelial vasodilatory response is intact in sepsis and microvascular thrombosis is not the predominant factor in the observed decrease in microcirculatory blood flow. Thus, an ideal agent to recruit the microcirculation in sepsis should have endothelium modulator and vasodilator characteristics, such as a nitric oxide (NO) donor [8,9]. However, a recent randomized clinical trial could not confirm the previous observation, that nitroglycerin improved microvascular perfusion in an open label setting [10].

Studies with magnesium $(\mathrm{Mg})$ and magnesium sulphate (MgS) have shown a peripheral (predominantly arteriolar) vasodilator effect with preserved cardiac function, within a large safety margin [11-13], not only indirectly by an endothelium-dependent release of NO $[14,15]$ but also directly via its ability to induce endothelium-independent vasodilation by a direct action on vascular smooth muscle as a calcium competitor. In addition to vasodilatory effects, infusion of $\mathrm{MgS}$ is also associated with other potential pro-microcirculatory effects, such as an increase in red blood cell deformability, reduction of platelet aggregation, anti-inflammatory effects and maintenance of endothelial integrity [16-19].

However, up to date the effect of MgS infusion on microvascular perfusion in septic patients, is unknown. Our study aims to test the hypothesis that MgS infusion may improve sublingual microcirculatory perfusion in patients with severe sepsis and septic shock.

\section{Methods \\ Setting}

The study was performed during an 8-months period in 2010 in a closed-format 15-bed mixed ICU in a university hospital. It was designed as a prospective, single-centre, open-label trial. Patients were included with less than 48 hrs duration of severe sepsis or septic shock as defined by the International Sepsis Definition Conference [20]. Exclusion criteria were pregnancy, oral bleeding, age $<18$ years, liver cirrhosis, acute arrhythmias, advanced malignancy or a mean arterial pressure (MAP) < $65 \mathrm{mmHg}$ refractory to vasopressors. The study was carried out in compliance with the Helsinki Declaration and approved by the local ethics committee (Kauno Regioninis Biomedicininiu Tyrimu Etikos Komitetas, $201003.03 \mathrm{nr}$ BE-2-6) and informed consent was obtained from each patient, according to applicable laws.

\section{Protocol and data collection}

All patients were equipped with an arterial line and central venous catheter or a pulmonary artery catheter (TD-I, B.Braun Medical, Bethlehem, USA). Prior to the start of MgS infusion, all patients followed a strict protocol to optimize systemic hemodynamic parameters in accordance with international guidelines for management of sepsis [21]. Patients were resuscitated such that mean MAP was $\geq 65 \mathrm{~mm} \mathrm{Hg}$, central venous pressure no less than $8 \mathrm{~mm} \mathrm{Hg}$ and mixed venous saturation $\left(\mathrm{SvO}_{2}\right) \geq 65 \%$ or central venous saturation $\left(\mathrm{S}(\mathrm{c}) \mathrm{vO}_{2}\right) \geq$ $70 \%$. Red blood cell transfusion trigger was a haematocrit $<25 \%$. Sedation and analgesia was provided with midazolam and fentanyl.

After achieving these therapeutic endpoints, MgS infusion was started at a rate of $2 \mathrm{~g}$ over 1 hour. For safety reasons, a sustained MAP $<65 \mathrm{~mm} \mathrm{Hg}$ during infusion despite protocolized treatment constituted a reason to stop MgS infusion permanently.

The following data were recorded at baseline: general characteristics, Acute Physiology and Chronic Health Evaluation II (APACHE II) score, calculated over the first 24 hrs following ICU admission and Sequential Organ Failure Assessment (SOFA) score, calculated at study time. Directly prior to and within 10 minutes after cessation of MgS infusion systemic hemodynamic variables, sublingual SDF images and standard laboratory tests, including arterial and central/mixed venous blood gasses were obtained. ICU and hospital length of stay (LOS) and mortality were registered afterwards.

\section{Videomicroscopic measurements and analysis}

Images of the sublingual microcirculation were obtained with SDF videomicroscopy (Microscan ${ }^{\circledR}$, Microvision Medical, Amsterdam, the Netherlands) [3]. After gentle removal of saliva and other secretions by an isotonic saline-drenched gauze, the device was applied to sublingual region, avoiding pressure artifacts by establishing a threshold-image. Sequences of 20 seconds from at least three areas were recorded on hard disk using a personal computer and AVA v3.0 software (Microvision medical, Amsterdam, The Netherlands). Video clips were blindly analyzed offline by two investigators in random order to prevent coupling. Assessment of microcirculatory parameters of convective oxygen transport (microvascular flow index (MFI) and proportion of perfused vessels $(\mathrm{PPV})$ ), and diffusion distance (perfused vessel density (PVD) and total vessel density (TVD)) was done according to published recommendations [22]. Vessels were separated into large (mostly venules) and small (mostly capillaries) using a diameter cutoff value of $20 \mu \mathrm{m}$. The final MFI score is the average values of $3 \times 4$ quadrants. Heterogeneity index was calculated as the difference between the highest and lowest MFI, divided by the 
mean MFI of all sublingual sites at a single time point [23].

\section{Statistical analysis}

Primary outcome is sublingual MFI of small vessels. We anticipated a standard deviation in difference of response of 0.5 . We calculated a sample size of 14 patients to detect a absolute difference of 0.4 in a twosided test with 0.05 type I error and a $80 \%$ probability. The Statistical Package for Social Sciences (SPSS 15.1 for Windows, Chicago, USA) was used for statistical analysis. With respect to small numbers data are presented as the median (25th-75th percentiles) and analyzed with non-parametric Wilcoxon signed rank test and Spearman's rho for correlations. A $p$ value $<0.05$ was considered significant.

\section{Results \\ Patients}

Fourteen patients (12 with septic shock and 2 with severe sepsis) with a median APACHE II score of 20 were enrolled, within 24 hours after the initial sepsis resuscitation. Baseline characteristics are summarized in Table 1 . Hospital mortality was $57 \%$ and all patients survived the first day after MgS infusion. A source of infection was confirmed in all cases. No predefined sustained hypotension during $\mathrm{MgS}$ infusion was reported.

Table 1 Baseline characteristics

\begin{tabular}{ll}
\hline Age, yrs & $62(42-74)$ \\
\hline Gender, male/female, $n$ & $8 / 6$ \\
\hline Source of sepsis, $\mathrm{n}$ & 4 \\
$\quad$ Lung & 7 \\
$\quad$ Abdomen & 1 \\
$\quad$ Urinary tract & 2 \\
$\quad$ Skin and soft tissues & $8(57)$ \\
\hline Hospital mortality, $\mathrm{n}(\%)$ & $5(3-11)$ \\
\hline ICU length of stay, days & $20(14-26)$ \\
\hline APACHE II score & $8(5-10)$ \\
\hline SOFA score & 12 \\
\hline Vasopressors, $\mathrm{n}$ & $5 ; 8.0(5.5-9.0)$ \\
$\quad$ Dopamine, $\mathrm{n} ; \mathrm{\mu g} / \mathrm{kg}$ per min & $9 ; 0.12(0.06-0.23)$ \\
$\quad$ Norepinephrine, $\mathrm{n} ; \mu \mathrm{g} / \mathrm{kg}$ per min & 13 \\
\hline Mechanical ventilation, $\mathrm{n}$ & $5(5-5)$ \\
$\quad$ PEEP, cm H2O & $55(50-55)$ \\
\hline FIO2, \% & $0.90(0.75-0.99)$ \\
\hline Total magnesium, mEq/l & $4.1(3.7-4.4)$ \\
\hline Potassium, mEq/l & $30(27-36)$ \\
\hline Hematocrit, \% &
\end{tabular}

APACHE, Acute Physiology and Chronic Health Evaluation; SOFA, Sepsisrelated Organ Failure Assessment; PEEP, positive end-expiratory pressure. Data are presented as median $\left(25^{\text {th }}-75^{\text {th }}\right.$ percentiles). Normal value for total magnesium is $0.9-1.2 \mathrm{mEq} / \mathrm{l}$.

\section{Hemodynamic data}

No significant difference in systemic hemodynamic variables was found between baseline and after $\mathrm{MgS}$ infusion (Table 2). Furthermore, we did not observe any significant difference pre and post $\mathrm{MgS}$ infusion in the primary endpoint MFI of small vessels: 2.25(1.98-2.69) vs. $2.33(1.96-2.62), \mathrm{p}=0.65$ (Figure 1 ). Other variables of microcirculatory perfusion were also unaltered (Table 3). In the overall unchanged microvascular perfusion there was a non-significant trend to an inverse linear relationship between the changes of MFI of small vessels and baseline values of MFI of small vessels $(y=-0.7260 \times$ $+1.629, r^{2}=0.270, p=0.057$, Figure 2). We also observed non-significant trends of inverse linear relationship between the changes in TVD of small vessels and baseline values. (Figure 3). Baseline value for total $\mathrm{Mg}$ was 0.9 (0.75-0.99); normal value for total magnesium is 0.9-1.2 $\mathrm{mEq} / \mathrm{l}$. The correlation between baseline $\mathrm{Mg}$ concentrations and the change in MFI pre- and post MgS infusion was non-significant $\left(r_{s}=-0.165, p=0.67\right)$.

\section{Discussion}

To our knowledge, this is the first study in which the effect of $\mathrm{Mg}$ on the human microcirculation is visualized directly in patients with sepsis. The main finding of our study is that MgS infusion had no effect on both sublingual microvascular perfusion and systemic hemodynamic variables in this setting. This is not in line with previous observations, that evaluated the effect of $\mathrm{MgS}$ on microcirculatory perfusion under non-septic conditions. In vivo plethysmography of the forearm in healthy volunteers during intra-arterial $\mathrm{MgS}$ infusion revealed a

Table 2 Systemic hemodynamic data

\begin{tabular}{|c|c|c|c|}
\hline & Baseline & MgS & $\begin{array}{c}p \\
\text { Value }\end{array}$ \\
\hline Heart rate, beats/min & $98(85-113)$ & $94(83-115)$ & 0.98 \\
\hline Mean arterial pressure, $\mathrm{mm} \mathrm{Hg}$ & $71(70-75)$ & $70(67-73)$ & 0.22 \\
\hline Central venous pressure, $\mathrm{mm} \mathrm{Hg}$ & $12(12-13)$ & $12(11-13)$ & 0.29 \\
\hline Vasopressors, $\mathrm{n}$ & 12 & 12 & \\
\hline $\begin{array}{l}\text { Dopamine, } n ; \mu g / k g \text { per } \\
\text { min }\end{array}$ & $5 ; 8.0(5.5-9.0)$ & $\begin{array}{l}5 ; 6.0(5.5- \\
12.0)\end{array}$ & 0.41 \\
\hline $\begin{array}{l}\text { Norepinephrine, } \mathrm{n} ; \mu \mathrm{g} / \mathrm{kg} \\
\text { per min }\end{array}$ & $\begin{array}{c}9 ; 0.12(0.06- \\
0.23)\end{array}$ & $\begin{array}{l}9 ; 0.12(0.06- \\
0.25)\end{array}$ & 0.31 \\
\hline $\begin{array}{l}\text { Central venous oxygen } \\
\text { saturation, } n ; \%\end{array}$ & 9; 73(71-74) & $9 ; 72(72-73)$ & 0.39 \\
\hline $\begin{array}{l}\text { Mixed venous oxygen saturation, } \\
\mathrm{n} ; \%\end{array}$ & $5 ; 68(65-72)$ & $5 ; 69(65-71)$ & 0.72 \\
\hline Cardiac output, $n ; \mathrm{L} / \mathrm{min}$ & $5 ; 5.4(4.6-6.8)$ & $5 ; 5.5(4.8-6.4)$ & 0.59 \\
\hline Lactate, $\mathrm{mmol} / \mathrm{L}$ & $2.7(2.4-3.6)$ & $2.7(2.2-3.7)$ & 0.78 \\
\hline $\mathrm{pH}$ & $\begin{array}{l}7.35(7.29- \\
7.44)\end{array}$ & $\begin{array}{l}7.38(7.30- \\
7.46)\end{array}$ & 0.07 \\
\hline
\end{tabular}

$\mathrm{MgS}$, magnesium sulphate. Data are presented as median $\left(25^{\text {th }}-75^{\text {th }}\right.$ percentiles). 


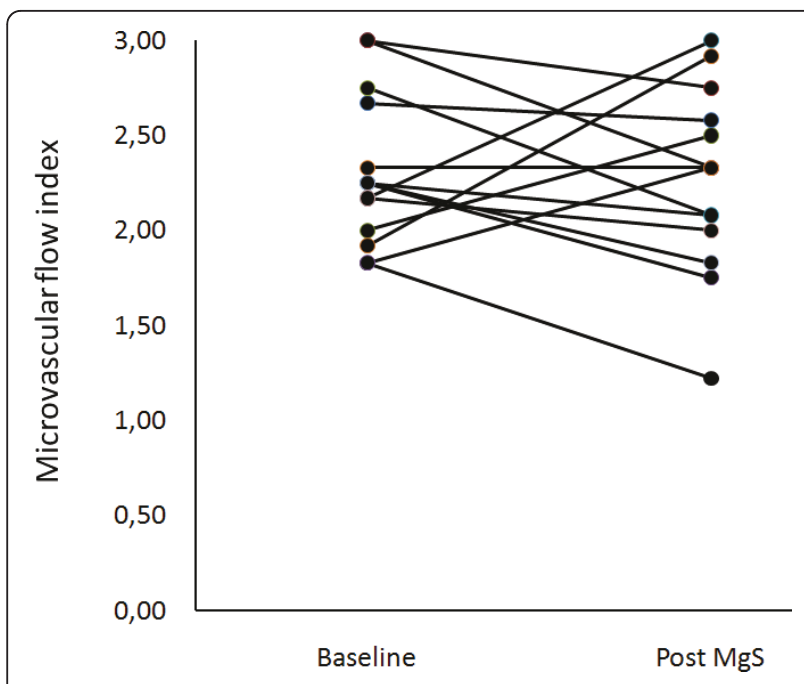

Figure 1 Change of microvascular flow index pre- and post magnesium sulphate infusion

marked increased in blood flow. In an animal model with direct in-vivo microscopy of the microcirculation, both topical and intravenous application of $\mathrm{Mg}$-compounds demonstrated vasodilatory effects in mesenteric arterioles $(10-20 \mu \mathrm{m})$ and venules $(15-30 \mu \mathrm{m})$, that could not be blocked by cyclo-oxygenase inhibition [24]. This effect was also observed during catecholamineinduced vasoconstriction [25].

The discrepancy between these results and our observations may in part be explained by a difference in technique. Plethysmography incorporates artiolar, capillary and venular blood flow. In sepsis however, a heterogeneous distribution of altered capillary blood flow is observed, often despite maintenance of both artial and venular blood flow. In contrast to plethysmography, SDF enables discrimination between these different vascular compartments. Furthermore, sublingual SDF imaging may not necessarily reflect microvascular perfusion abnormalities in vascular beds of other organs [26]. Whether the sensitivity of software-supported analysis of TVD of vessels equals to direct diameter measurements of vessels during in-vivo microscopy remains to be established and is very sensitive to adequate focus.

The classical response to overcome microvascluar perfusion abnormalities in shock has always been to raise arterial pressure by means of vasopressors, in order to increase the net perfusion pressure over the microvascular compartment. However, according to physiological theory, the drop in perfusion pressure prior to the microcirculation is equal to the increase in artiolar resistance, thus reducing its pro-microcirculatory flow effect [27]. Recent studies indeed failed to demonstrate a promicrocirculatory effect after a stepwise increase of blood pressure with norepinephrine [28,29]. Although the alternative concept of vasodilation to recruit microcirculatory perfusion in sepsis is tempting [30], up till now no clinically available vasodilators with pro-microcirculatory characteristics have been discovered. Despite promising results in a small group of patients [9], nitroglycerin showed no effect on microcirculatory perfusion in a randomized placebo controlled trial in patients with severe sepsis and septic shock [10]. Both the latter study and the presented trial have in common that a vasodilator was infused on top of a strict resuscitation protocol, making hypovolemia unlikely. Even under well-descript vasodilatory effects of epidural anesthesia, hypervolemic hemodilution completely blunted microcirculatory changes in flow and capillary density of the vaginal mucosa [31]. The absence of effect of a vasodilator in this setting, both on macro- and microcirculatory variables, may be in line with maximal pre-capillary smooth muscle relaxation prior to the start of the intervention. This is particularly of note since, unlike nitroglycerin, $\mathrm{MgS}$ has an additional non-endothelium dependent pathway to exert its vasodilatory capacities, by a direct action on vascular smooth muscle relaxation as a calcium antagonist [15].

Our study has a number of limitations. Due to the open label setting and relatively small numbers a modest effect of MgS infusion on microcirculatory perfusion

Table 3 Microcirculation perfusion data

\begin{tabular}{lccc}
\hline & Baseline & MgS & $\boldsymbol{p}$ Value \\
\hline Microvascular flow index of small vessels & $2.25(1.98-2.69)$ & $2.33(1.96-2.62)$ & 0.65 \\
\hline Microvascular flow index of large vessels & $3.00(3.00-3.00)$ & $3.00(3.00-3.00)$ & 0.79 \\
\hline Proportion of perfused small vessels, $\%$ & $81.5(78.8-89.3)$ & $85.0(79.3-86.3)$ & \\
\hline Total vessel density of small vessels, $\mathrm{mm} / \mathrm{mm}^{2}$ & $26.9(23.2-30.1)$ & $27.8(24.4-29.5)$ & 0.64 \\
\hline Total vessel density of others vessels, $\mathrm{mm} / \mathrm{mm}^{2}$ & $7.4(6.2-8.9)$ & $6.6(5.8-8.0)$ & 0.86 \\
\hline Perfused vessel density of small vessels, $\mathrm{n} / \mathrm{mm}$ & $13.4(11.8-15.8)$ & $13.6(11.5-15.1)$ & 0.26 \\
\hline Perfused vessel density of other vessels, $\mathrm{n} / \mathrm{mm}$ & $4.2(3.7-4.7)$ & $4.0(3.3-5.0)$ & 0.59 \\
\hline Heterogeneity index & $0.30(0.08-0.54)$ & $0.42(0.26-0.50)$ & 0.97 \\
\hline
\end{tabular}

MgS, magnesium sulphate. Data are presented as median $\left(25^{\text {th }}-75^{\text {th }}\right.$ percentiles). 


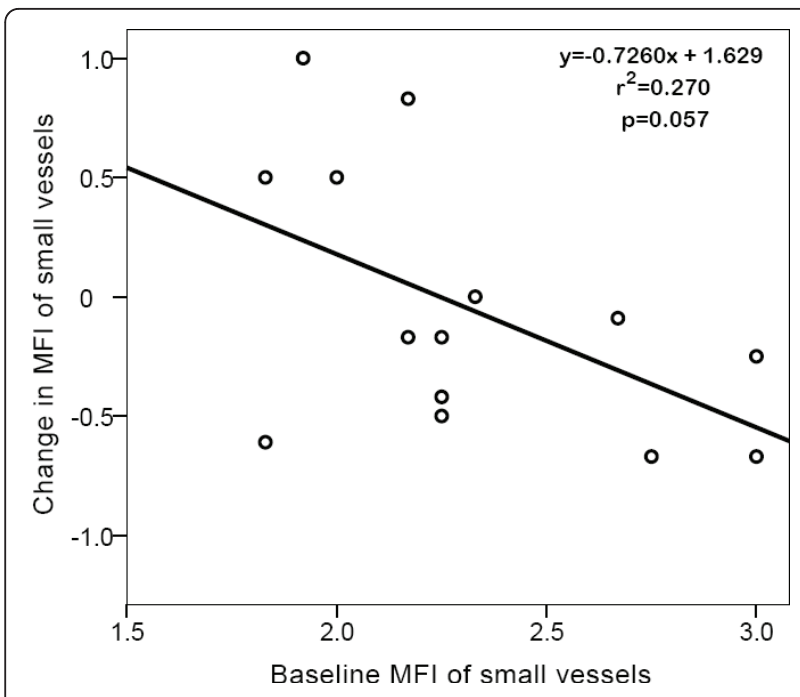

Figure 2 Linear relationship between baseline microvascular flow index and change pre- and post magnesium sulphate infusion. microvascular flow index, MFI

may have remained unnoticed. Baseline MFI was decreased despite resuscitation, but only to a moderate extend. Although this may have blunted a potential pro-microcirculatory effect of $\mathrm{MgS}$, we only observed a non-significant and weak correlation between baseline MFI and change in MFI in response to therapy. It must be stated however, that post-hoc linear regression analysis itself is limited by the narrow range of variables. We deliberately chose this strategy, since we consider it key not to replace therapeutic macro-hemodynamic strategies by micro-hemodynamic strategies, but to add micro-hemodynamic strategies in case of

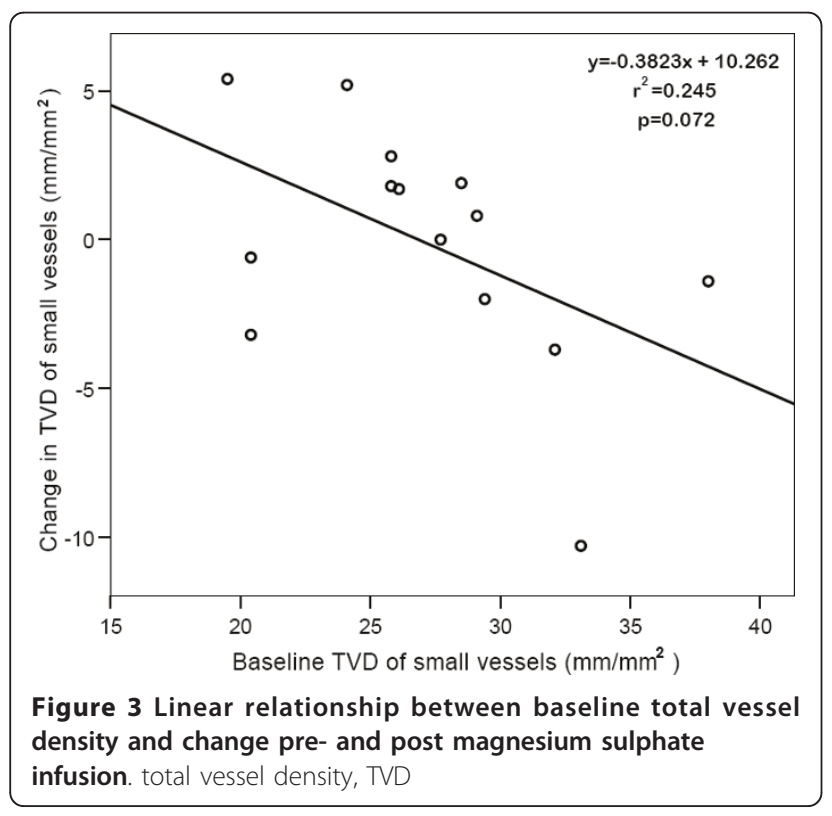

remaining microcirculatory abnormalities, despite optimal macro-hemodynamic resuscitation. In our study we used a continuous fixed dose of MgS without bolus due to safety reason, since some data show, that higher doses of MgS may inhibit catecholamine release $[32,33]$. Endothelium-independent vasodilation is associated with venous $\mathrm{Mg}$ concentrations, but the endothelium-mediated vasodilatory pathway of $\mathrm{Mg}$ appears to be activated, irrespective of its plasma levels [14]. In the present study there was no correlation between baseline $\mathrm{Mg}$ concentrations and the change in MFI pre- and post MgS infusion. We failed to report plasma Mg concentrations after infusion. The observation period after the intervention was without delay. This may have been too short to allow microcirculatory alterations to respond to the intervention. On the other hand, longer observation periods in an open label setting carry a considerable risk of improvement over time, irrespective of the intervention itself. Therefore, we cannot rule out that a higher dose, a different loading regiment, suppletion to a pre-defined plasma $\mathrm{Mg}$ concentrations or a longer post-intervention observation period may have revealed more potential of $\mathrm{MgS}$ infusion for the improvement of microcirculatory perfusion in sepsis.

\section{Conclusion}

In the setting of severe sepsis and septic shock sublingual microcirculatory alterations were observed despite fulfillment of sepsis resuscitation guidelines. After infusion of a limited and fixed dose of MgS, microcirculatory perfusion did not improve over time.

\section{List of abbreviations}

OPS: orthogonal polarization spectral; SDF: sidestream dark field; NO: nitric oxide; Mg: magnesium; MgS: magnesium sulphate; MAP: mean arterial pressure; $\mathrm{SvO}_{2}$ : mixed venous saturation; $\mathrm{S}(\mathrm{c}) \mathrm{vO}_{2}$ : central venous saturation; APACHE: Acute Physiology and Chronic Health Evaluation; SOFA: Sequential Organ Failure Assessment; LOS: length of stay; MFI: microvascular flow index PPV: proportion of perfused vessels; PVD: perfused vessel density total vessel density (TVD)

\section{Author details}

'Department of Intensive Care Medicine, Hospital of Lithuanian University of Health Sciences, A.Mickeviciaus g.9 Kaunas, LT 44307, Lithuania. ${ }^{2}$ Department of Intensive Care Medicine, Medical Center Leeuwarden, Henri Dunantweg 2, Leeuwarden, 8901 BR, the Netherlands. ${ }^{3}$ Department of Translational Physiology, Academic Medical Center, Amsterdam, the Netherlands.

\section{Authors' contributions}

AP conceived the study, performed SDF imaging and wrote the first draft; NV analyzed SDF images; VP participated in the design of the study; MK was responsible for data acquisition; $C B$ performed statistical analysis and wrote the final manuscript. All authors read and approved the final manuscript.

\section{Competing interests}

The authors declare that they have no competing interests.

Received: 9 March 2011 Accepted: 14 June 2011

Published: 14 June 2011 


\section{References}

1. Ince C: The microcirculation is the motor of sepsis. Crit Care 2005, 9(Suppl 4):S13-S19.

2. Groner W, Winkelman JW, Harris AG, Ince C, Bouma GJ, Messmer K, Nadeau RG: Orthogonal polarization spectral imaging: a new method for study of the microcirculation. Nat Med 1999, 5:1209-1212.

3. Goedhart P, Khalilzada M, Bezemer R, Merza J, Ince C: Sidestream Dark Field (SDF) imaging: a novel stroboscopic LED ring-based imaging modality for clinical assessment of the microcirculation. Opt. Express 2007, 15:15101-15114.

4. De Backer D, Creteur J, Preiser JC, Dubois MJ, Vincent JL: Microvascular blood flow is altered in patients with sepsis. Am J Respir Crit Care Med 2002, 166:98-104.

5. Sakr Y, Dubois MJ, De Backer D, Creteur J, Vincent JL: Persistent microcirculatory alterations are associated with organ failure and death in patients with septic shock. Crit Care Med 2004, 32:1825-1831.

6. Buwalda $M$, Ince $C$ : Opening the microcirculation: can vasodilators be useful in sepsis? Intensive Care Med 2002, 28:1208-1217.

7. De Backer D, Creteur J, Dubois MJ, Sakr Y, Koch M, Verdant C, Vincent JL: The effects of dobutamine on microcirculatory alterations in patients with septic shock are independent of its systemic effects. Crit Care Med 2006, 34:403-408.

8. Trzeciak S, Cinel I, Phillip Dellinger R, Shapiro NI, Arnold RC, Parrillo JE, Hollenberg SM: Resuscitating the microcirculation in sepsis: the central role of nitric oxide, emerging concepts for novel therapies, and challenges for clinical trials. Acad Emerg Med 2008, 15:399-413.

9. Spronk PE, Ince C, Gardien MJ, Mathura KR, Oudemans-van Straaten HM, Zandstra DF: Nitroglycerin in septic shock after intravascular volume resuscitation. Lancet 2002, 360:1395-1396.

10. Boerma EC, Koopmans M, Konijn A, Kaiferova K, Bakker AJ, van Roon EN, Buter H, Bruins N, Egbers PH, Gerritsen RT, Koetsier PM, Kingma WP, Kuiper MA, Ince C: Effects of nitroglycerin on sublingual microcirculatory blood flow in patients with severe sepsis/septic shock after a strict resuscitation protocol: A double-blind randomized placebo controlled trial. Crit Care Med 2010, 38:93-100.

11. James MF, Cork RC, Dennett JE: Cardiovascular effects of magnesium sulphate in the baboon. Magnesium 1987, 6:314-324

12. Nakaigawa $Y$, Akazawa $S$, Shimizu $R$, Ishii $R$, Ikeno $S$, Inoue $S$, Yamato $R$ : Effects of magnesium sulphate on the cardiovascular system, coronary circulation and myocardial metabolism in anaesthetized dogs. $\mathrm{Br} \mathrm{J}$ Anaesth 1997, 79:363-368.

13. Boschat J, Gilard M, Etienne $Y$, Roriz R, Jobic $Y$, Penther P, Blanc JJ: [Hemodynamic effects of intravenous magnesium sulfate in man]. Arch Mal Coeur Vaiss 1989, 82:361-364.

14. Haenni $A$, Johansson $K$, Lind $L$, Lithell $H$ : Magnesium infusion improves endothelium-dependent vasodilation in the human forearm. Am J Hypertens 2002, 15:10-15.

15. Teragawa H, Kato M, Yamagata T, Matsuura H, Kajiyama G: Magnesium causes nitric oxide independent coronary artery vasodilation in humans. Heart 2001, 86:212-216

16. Schauf B, Becker S, Abele H, Klever T, Wallwiener D, Aydeniz B: Effect of magnesium on red blood cell deformability in pregnancy. Hypertens Pregnancy 2005, 24:17-27.

17. Gries A, Bode C, Gross S, Peter K, Bohrer H, Martin E: The effect of intravenously administered magnesium on platelet function in patients after cardiac surgery. Anesth Analg 1999, 88:1213-1219.

18. Mazur A, Maier JA, Rock E, Gueux E, Nowacki W, Rayssiguier Y: Magnesium and the inflammatory response: potential physiopathological implications. Arch Biochem Biophys 2007, 458:48-56.

19. Dong JF, Cruz MA, Aboulfatova K, Martin C, Choi H, Bergeron AL, Martini SR, Kroll $\mathrm{MH}$, Kent TA: Magnesium maintains endothelial integrity, upregulates proteolysis of ultra-large von Willebrand factor, and reduces platelet aggregation under flow conditions. Thromb Haemost 2008, 99:586-593.

20. Levy MM, Fink MP, Marshall JC, Abraham E, Angus D, Cook D, Cohen J, Opal SM, Vincent JL, Ramsay G: 2001 SCCM/ESICM/ACCP/ATS/SIS International Sepsis Definitions Conference. Crit Care Med 2003, 31:1250-1256.

21. Dellinger RP, Levy MM, Carlet JM, Bion J, Parker MM, Jaeschke R, Reinhart K, Angus DC, Brun-Buisson C, Beale R, Calandra T, Dhainaut JF, Gerlach H, Harvey M, Marini JJ, Marshall J, Ranieri M, Ramsay G, Sevransky J,
Thompson BT, Townsend S, Vender JS, Zimmerman JL, Vincent JL: Surviving Sepsis Campaign: international guidelines for management of severe sepsis and septic shock: 2008. Crit Care Med 2008, 36:296-327.

22. De Backer D, Hollenberg S, Boerma C, Goedhart P, Buchele G, OspinaTascon G, Dobbe I, Ince C: How to evaluate the microcirculation: report of a round table conference. Crit Care 2007, 11:R101.

23. Trzeciak S, Dellinger RP, Parrillo JE, Guglielmi M, Bajaj J, Abate NL, Arnold RC, Colilla S, Zanotti S, Hollenberg SM: Early microcirculatory perfusion derangements in patients with severe sepsis and septic shock: relationship to hemodynamics, oxygen transport, and survival. Ann Emerg Med 2007, 49:88-98.

24. Nishio A, Gebrewold A, Altura BT, Altura BM: Comparative vasodilator effects of magnesium salts on rat mesenteric arterioles and venules. Arch Int Pharmacodyn Ther 1989, 298:139-163.

25. Nishio A, Gebrewold A, Altura BT, Altura BM: Comparative effects of magnesium salts on reactivity of arterioles and venules to constrictor agents: an in situ study on microcirculation. J Pharmacol Exp Ther 1988, 246:859-865.

26. Boerma EC, van der Voort PHJ, Spronk PE, Ince C: Relationship between sublingual and intestinal microcirculatory perfusion in patients with abdominal sepsis. Crit Care Med 2007, 35:1055-1060.

27. Boerma EC, Ince $C$ : The role of vasoactive agents in the resuscitation of microvascular perfusion and tissue oxygenation in critically ill patients. Intensive Care Med 2010, 36:2004-2018.

28. Jhanji S, Stirling S, Patel N, Hinds CJ, Pearse RM: The effect of increasing doses of norepinephrine on tissue oxygenation and microvascular flow in patients with septic shock*. Crit Care Med 2009.

29. Dubin A, Pozo MO, Casabella CA, Palizas F, Murias G, Moseinco MC, Kanoore Edul VS, Estenssoro E, Ince C: Increasing arterial blood pressure with norepinephrine does not improve microcirculatory blood flow: a prospective study. Crit Care 2009, 13:R92.

30. Buwalda M, Ince C: Opening the microcirculation: can vasodilators be useful in sepsis? Intensive Care Med 2002, 28:1208-1217.

31. van den Oever HLA, Dzoljic M, Ince C, Hollmann MW, Mokken FC: Orthogonal polarization spectral imaging of the microcirculation during acute hypervolemic hemodilution and epidural lidocaine injection. Anesth Analg 2006, 103:484-487.

32. James MF, Cronjé L: Pheochromocytoma crisis: the use of magnesium sulfate. Anesth Analg 2004, 99:680-686.

33. James MF, Beer RE, Esser JD: Intravenous magnesium sulfate inhibits catecholamine release associated with tracheal intubation. Anesth Analg 1989, 68:772-776.

\section{Pre-publication history}

The pre-publication history for this paper can be accessed here: http://www.biomedcentral.com/1471-2253/11/12/prepub

doi:10.1186/1471-2253-11-12

Cite this article as: Pranskunas et al:: Microcirculatory changes during open label magnesium sulphate infusion in patients with severe sepsis and septic shock. BMC Anesthesiology 2011 11:12

\section{Submit your next manuscript to BioMed Central and take full advantage of:}

- Convenient online submission

- Thorough peer review

- No space constraints or color figure charges

- Immediate publication on acceptance

- Inclusion in PubMed, CAS, Scopus and Google Scholar

- Research which is freely available for redistribution 